\title{
Estado Novo e a conquista de espaços territoriais e simbólicos
}

\section{Lucia Lippi Oliveira*}

A gradeço o convite para participar deste colóquio, o que me permite voltar ao Estado Novo mais uma vez. Já me encontro em uma fase da vida em que, para falar de qualquer assunto, volto aos tempos passados ${ }^{1}$ !

Minha primeira incursão no tema do Estado Novo foi no final dos anos 1970, quando coordenei um projeto no Centro de Pesquisa e Documentação de História Contemporânea do Brasil (Cpdoc) da Fundação Getúlio Vargas (FGV). Estávamos sob a ditadura militar, e voltar à ditadura anterior era possível e necessário. Desse projeto saiu o livro Estado Novo: ideologia e poder, publicado em 1982, que, embora esgotado, pode ser consultado na estante virtual do portal do Cpdoc.

Nesse livro, publiquei artigos sobre Azevedo Amaral e Almir de Andrade, representantes da modernização e da tradição, respectivamente. Esses dois grandes eixos passaram a fazer parte de meu caminho, para lidar com intelectuais, cultura e identidade nacional.

No eixo da modernização, andei escrevendo sobre o papel de editoras, como a José Olympio; sobre o espaço do rádio e do cinema no Estado Novo, principalmente do Instituto Nacional de

Lucia Lippi Oliveira é Socióloga, pesquisadora e Professora do Centro de Pesquisa e Documentação de História Contemporânea do Brasil (CPDOC) da Fundação Getúlio Vargas (FGV).

1 Conferência apresentada no colóquio "Variações sobre um tema: interpretações do Brasil e do Estado Novo", realizado em Florianópolis, na Universidade Federal de Santa Catarina (UFSC), em novembro de 2007. 
Cinema Educativo (INCE), onde foi muito importante a atuação do antropólogo Roquette-Pinto.

No eixo da tradição, tenho passeado pela atuação do Serviço do Patrimônio Histórico e Artístico Nacional, escrevendo e falando sobre Rodrigo Melo Franco de Andrade e Lucio Costa - figura de intelectual maior tanto da vertente moderna quanto da tradicional, já que foi Diretor do Departamento de Tombamento do Sphan de 1937 até os anos 1970.

Em 2002, voltei ao tema do Estado Novo. Escrevi um artigo sobre Lourival Fontes, no qual fiz uma releitura do imaginário historiográfico sobre o "famoso" Diretor do Departamento de Imprensa e Propaganda (DIP). Esse artigo foi publicado no livro organizado por Helena Bomeny, que se chama Constelação Capanema, também disponível no portal do Cpdoc. Posso dizer que eu normalmente produzo contra a corrente. Gosto de estudar figuras menores, ou mesmo perdedoras; penso que elas informam mais sobre os cânones do mainstream do que os vitoriosos, que tendem a atribuir sua vitória à justeza de suas posições.

Conhecer os projetos de identidade no Brasil tem sido o objetivo dos diferentes textos nos quais tratei dos intelectuais brasileiros ao longo do século XX. O Estado Novo oferece um exemplo significativo de construção de identidade na medida em que, nesse período da história brasileira, foi explicitado o trabalho simbólico de inúmeros intelectuais, ideólogos do regime, ocupados em definir e implementar uma política que expressasse, que representasse, que produzisse a unidade nacional. Essa marca aparece nos campos já conhecidos da Educação, da Educação Física, das festas e comemorações, da defesa do patrimônio histórico; assim como na criação do Museu Imperial, em Petrópolis, e do Parque Nacional do Itatiaia.

Foi a compreensão da importância do espaço territorial como elemento constitutivo da identidade nacional no Brasil que me levou a realizar um projeto comparativo entre o Brasil e os Estados Unidos da América, países onde a questão territorial e o alargamento de fronteiras foram fundamentais. Isso se encontra em meu livro Americanos: representações da identidade nacional no Brasil e nos EUA. Minha hipótese, hoje posso dizer minha tese, é a de que, nesses 
dois países, a Geografia forneceu o mais forte embasamento para os modelos de identidade nacional que tiveram êxito.

Ao envolver-me mais recentemente em estudos sobre urbanismo, deparei-me com informações que reafirmam tal perspectiva. A construção da nova capital do estado de Goiás, a cidade de Goiânia, inaugurada em 1941, foi um importante marco na política de conquista do interior. Goiânia, assim como a cidade de Volta Redonda (acoplada à siderúrgica), fez parte da política de ocupação de novos territórios, da montagem de comunicações entre espaços anteriormente isolados. Isso, é preciso lembrar, já estava presente desde o início dos anos 1930, quando foi empreendido grande esforço para constituir um serviço de Correios e Telégrafos de abrangência nacional. Só para exemplificar: no início dos anos 1930, foram construídas mais de 140 novas agências pelo Brasil afora, que obedeceram a certos padrões de construção. Vemos isso até hoje quando chegamos a uma cidade qualquer e olhamos em volta; sabemos imediatamente que tal prédio é da agência dos Correios do lugar.

Essas ações, para além de sua diversidade, podem ser pensadas segundo um grande princípio: ocupar os espaços vazios. Sua abrangência faz-me pensar que devemos retornar ao tema da ocupação do Oeste e à figura de Cassiano Ricardo, principalmente em seu livro A marcha para o Oeste.

Cassiano Ricardo ficou famoso pela publicação de Martin Cererê, em 1928, livro composto de 44 poemas, com os quais desejou transmitir aos jovens o amor ao Brasil.

O ano de 1928 deve ser enfatizado, já que nele foram publicados Retrato do Brasil, de Paulo Prado, Macunaíma, de Mário de Andrade, e Martin Cererê, de Cassiano Ricardo. São, por assim dizer, três "retratos" do Brasil e dos brasileiros. Cada um deles procurou representar o homem brasileiro para além da exaltação da natureza. Ao elaborarem tais retratos, os autores criaram uma narrativa sobre os tipos nacionais e, com ela, pretenderam superar o pessimismo, a marca da incapacidade que caracterizava figuras como Jeca Tatu, de Monteiro Lobato, em sua primeira fase.

Com a obra A marcha para o Oeste, de 1940, Cassiano Ricardo estava dando sua contribuição fundamental para a montagem ide- 
ológica do Estado Novo. Sabemos que o Estado Novo teve como projeto mudar a imagem do Brasil e do homem brasileiro. Queria criar o homem novo - o trabalhador. A ocupação do interior e a recriação de tipos nacionais fizeram parte de um mesmo processo, voltado para criar uma narrativa sobre o trabalhador brasileiro.

Cassiano Ricardo (que pertenceu ao Movimento Verde-Amarelo, grupo que combatia a influência estrangeira) vai recuperar a figura do bandeirante. Para ele, não se tratava de aristocratas e arianos (como dizia Oliveira Vianna) nem de aventureiros pobres (como relatava José de Alcântara Machado). O bandeirante tinha mesmo uma baixa tecnologia, mas adaptou-se, aprendeu com os índios as técnicas de lidar com o ambiente e misturou-se com os da terra. Isso fez, segundo Cassiano, a experiência brasileira ser mesmo superior à norte-americana em sua conquista do Oeste. Aqui, criou-se um processo singular de modernidade. Tudo isso aparece em A marcha para o Oeste.

A busca da conquista do Oeste é apresentada como realização de um destino: juntar o litoral e o sertão, juntar o corpo e a alma da nação. A conquista do território, a expansão para o interior, é o destino que as elites litorâneas devem assumir. É preciso integrar homem e território, realizar um tipo de "imperialismo interno", cujo exemplo maior foi Rondon.

Para demarcar a relevância do bandeirante, Cassiano vai elaborar a distinção entre a cultura do café e a do açúcar. Segundo ele, a cultura do café, ou seja, a que gera a sociedade bandeirante, tem como razão de ser o movimento; exige a renovação da terra movendo-se para o interior, expande-se para o interior, recusa o sedentarismo, é democrática e empreendedora, tem o trabalho organizado como experiência básica e vai consolidar a identidade nacional. Já a cultura do açúcar, que deu origem à sociedade senhorial, tem ojeriza ao movimento, é aristocrática e hierarquizada, estável, conservadora.

Cassiano está contrapondo-se a Gilberto Freyre em Casa-grande $\mathcal{E}$ senzala e dialogando com Oliveira Vianna, ainda que discorde da interpretação do homem paulista apresentada por Vianna em Populações meridionais do Brasil. 
É preciso voltar a Oliveira Vianna sob nova perspectiva ao lidar com o território e a geografia. Eu já tinha lido artigos de Oliveira Vianna - publicados no livro Ensaios inéditos e no jornal $A$ Manhã (dirigido por Cassiano Ricardo) - em que o autor falava sobre a criação de novos territórios. Interpretei aquilo como decorrência de o autor ser "escriba de aluguel" do Estado Novo.

O livro mais recente de Maria Stella Bresciani (2005) sobre Oliveira Vianna fez-me voltar a esse autor e reconhecer que ele, para além da raça, destaca o meio como elemento central em sua análise. Em Evolução do povo brasileiro, ele fala em três grandes matrizes do povo brasileiro, que se caracterizam por histórias, organização e psicologia específicas - a do sertão, a das matas e a dos pampas. Segundo Vianna, elas explicam as dificuldades de criação de um todo nacional.

É interessante lembrar que Evolução do povo brasileiro é como passou a chamar-se, a partir de 1933, o texto 0 recenseamento de 1920 : o povo e sua evolução (1920). Esse texto e o livro Populações meridionais do Brasil são da mesma época e tratam do mesmo tema: a formação social, como já foi mencionado, do homem das matas (de Minas Gerais, do Rio de Janeiro e de São Paulo), sua história, organização e psicologia. O segundo volume dessa obra trata dos pampas.

O diagnóstico elaborado por Oliveira Vianna passa pelas diversas regiões, pelas diferentes raças, pelos vários tipos de moral social, pela mudança do mundo rural para o urbano; faz análise dos tipos sociais: o capanga, o cangaceiro, o coronel, o eleitor de cabresto; registra as especificidades de cada região e grupo. Segundo ele, os tipos geram usos e costumes, criam um direito costumeiro que não tem nada a ver com o arcabouço jurídico (a "constituição idealista" de que tanto fala). Coroando isso tudo fica sua pergunta básica: como construir a nacionalidade com essa diversidade? Qual a democracia ou civilização possível?

Bresciani (2005, p. 257) observa que, "sempre atento à força modeladora do meio, Oliveira Vianna preocupou-se, em seguida, com a distribuição das três raças, cuja diversidade e dispersão resultara em tipos étnicos regionais". A autora nota também que, ao verificar como os diversos segmentos étnicos distribuem-se sobre o território, ele procede à semelhança de outros autores, possivelmente guiados por Ratzel. 
Um dos "pais fundadores" da Geografia, Ratzel tem como premissa fundamental a ocupação efetiva de todo o território nacional. Segundo ele, é necessário consolidar o território, e isso se faz pela integração e pela ocupação. O solo não é apenas propriedade da nação, é sua essência. Suas idéias aparecem em diferentes vertentes do pensamento social no mundo ocidental e no Brasil.

Euclides da Cunha está entre aqueles que beberam água nessa fonte. Euclides da Cunha também já mostrara como o processo de ocupação do território e o contato com o solo tinham criado o sertanejo, um tipo biologicamente adaptado. Adaptado, isolado e abandonado. E sua mensagem mais forte: era preciso recuperar esse homem!

Podemos dizer que há um pensamento geográfico presente em várias vertentes deterministas e evolucionistas, assim como no modelo de crítica literária difundida no fim do século XIX. A importância da fórmula de Taine - meio, raça e momento - está registrada na maioria dos intérpretes do Brasil na virada do século XIX para o XX. Essas questões vêm sendo investigadas e afirmadas pelos geógrafos, principalmente por aqueles que vêm fazendo a leitura do pensamento geográfico no Brasil.

Retomando o pensamento social brasileiro dos anos 1920 e as interpretações do Brasil, sabemos que o combate ao federalismo da Primeira República é ponto central. O isolamento e o abandono das populações do interior e a concentração da população e da civilização no litoral aparecem como decorrentes do federalismo à brasileira.

Todos esses ingredientes fazem as propostas de redivisão territorial serem retomadas a partir de 1933 e implementadas durante o Estado Novo. Foi com a Constituição de 1937 que se criou uma lei geográfica que concedeu, em 1939, ao futuro Instituto Brasileiro de Geografia e Estatística (IBGE) o controle sobre a criação de municípios.

A redivisão territorial foi afinal realizada sob a coordenação do IBGE em 1941. Seu autor, Fábio de Macedo Soares, membro do grupo fundador do IBGE, publica na Revista Brasileira de Geografia um artigo que lança as bases da primeira regionalização oficial 
do país. O autor trabalha com o conceito de região natural para sustentar a divisão regional sugerida e implementada, a qual deveria englobar tanto aspectos físicos quanto econômicos. Sob influência da Geografia francesa, esse aluno de Pierre Deffontaine na Universidade do Distrito Federal (UDF) formula e implementa a divisão regional do país. Segundo Vidal de La Blache, é preciso lembrar que o conceito de região e a valorização do regionalismo são os eixos centrais da Geografia francesa.

Coube ao IBGE formar a base cartográfica para a realização do censo de 1940, considerado elemento fundamental para a implementação das políticas públicas do Estado brasileiro. A questão da identidade nacional também foi levada em conta no censo. Nele, havia três quesitos sobre naturalidade paterna, materna e língua falada no domicílio.

Macedo Soares é considerado figura fundamental na montagem de uma rede de coleta presente em quase todos os municípios brasileiros. A atuação geográfica, territorial, do Estado brasileiro consolidou-se, também, pela criação, em 1944, de cinco territórios: Amapá, Guaporé, Rio Branco, Iguaçu e Ponta Porã (os dois últimos foram extintos em 1946).

A relação entre as partes e o todo se encontra na política do Estado Novo, principalmente na atuação do IBGE, ao criar, em 1941, a divisão regional e, por assim dizer, inventar o Nordeste (antes, tudo o que estava acima da Bahia era chamado de "o Norte").

Os tipos nacionais também estão representados nas gravuras famosas de Percy Lau. Arquiteto, funcionário do IBGE, em suas ilustrações procurou aproximar tipos humanos e aspectos geográficos, visando promover a integração do povo ao território. O povoamento e a exploração das áreas desocupadas foram o eixo central da política de integração. Tanto o território quanto a economia eram vistos como um "arquipélago", ilhas cercadas de espaços despovoados. A valorização dos aspectos locais e regionais visava à unidade nacional. Assim, o seringueiro, o gaúcho, o vaqueiro do Nordeste, as rendeiras do Nordeste, principais ilustrações realizadas por Percy Lau, mostram como o homem e a natureza entrelaçam-se. Ou, dito de outra forma, ali se naturaliza o enraizamento dos tipos humanos retratados. 
De Euclides da Cunha a Capistrano de Abreu, de Oliveira Vianna a Cassiano Ricardo, passando pelo IBGE, estamos defrontando-nos com um discurso que, para compreender o Brasil ou propor a solução dos problemas nacionais, lida com a ocupação do interior ou do "sertão".

A marcha para ocupar o sertão parece ser tarefa épica de construção da nação. Os bandeirantes são a inspiração histórica para os novos empreendimentos de ocupação política e cultural do sertão que os bandeirantes já tinham conquistado. Nos anos 1940, cabia ao Estado realizar essa expansão interna, algo como "crescer por dentro", crescer do litoral para o interior.

Por fim, cabe observar que a outra ditadura do século XX, a militar, fará o mesmo com a outra grande região, o outro "sertão" - a Amazônia -, motivada por razões predominantemente geopolíticas.

\section{Referências bibliográficas}

ALMEIDA, R. S. A Geografia e os geógrafos do IBGE no período 1938-1998. Rio de Janeiro. Tese (Doutorado em Geografia). Universidade Federal do Rio de Janeiro, 2000.

BASTOS, E. R. Oliveira Vianna e a Sociologia no Brasil. In: BASTOS, E. R. \& MORAES, J. Q. (orgs.). O pensamento de Oliveira Vianna. Campinas: UNICAMP, 1993.

BRESCIANI, M. S. M. O charme da ciência e a sedução da objetividade: Oliveira Vianna entre os intérpretes do Brasil. São Paulo: UNESP, 2005.

DAOU, A. M. Tipos e aspectos do Brasil: imagens em imagem do Brasil. In: ROZENDAHL, Z. \& CORREAA, R. L. (orgs.). Paisagem, imaginário e espaço. Rio de Janeiro, 2001.

MAIA, J. M. E. Rússia americana... Rio de Janeiro: J. Zahar, no prelo. MORAES, A. C. R. Território e História do Brasil. São Paulo: Hucitec, 2002. 
MOREIRA, L. F. Meninos, poetas \& heróis: aspectos de Cassiano Ricardo do modernismo ao Estado Novo. São Paulo: USP, 2001.

OLIVEIRA, L. L. Uma leitura das leituras de Oliveira Vianna. In: BASTOS, E. R. \& MORAES, J. Q. (orgs.). O pensamento de Oliveira Vianna. Campinas: UNICAMP, 1993.

. Americanos: representações da identidade nacional no Brasil e nos EUA. Belo Horizonte: UFMG, 2000.

OLIVEIRA VIANNA, F. J. Ensaios inéditos. Campinas: UNICAMP, 1991. SOARES, F. M. Divisão regional do Brasil. Revista Brasileira de Geografia, Rio de Janeiro, ano 3, n. 2, p. 318-373, abr.-jun.1941.

SOUZA, C. V. A pátria geográfica: sertão e litoral no pensamento social brasileiro. Goiânia: UFG, 1997. 
